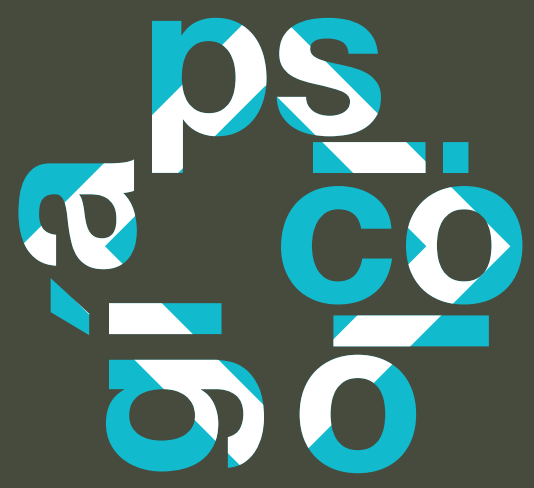

Anuario de

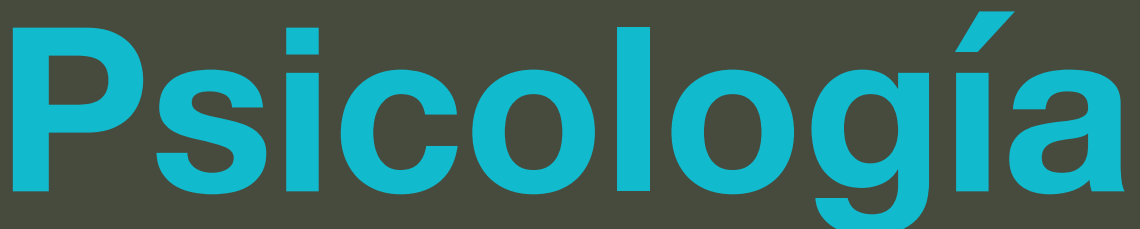

The UB Journal of Psychology | 49

Cristina Álvaro-Mora

cristinaalvaromora@gmail.com

\section{Miguel Ángel Serrano-Rosa}

m.angel.serrano@uv.es

Departamento de Psicobiología

Universidad de Valencia

Av. Blasco Ibáñez, 21

46010 Valencia

963983456

\section{Anuario de Psicología}

N.o $49|2019|$ págs. I8-3 I

Recibido: 3 de julio de 2018

Aceptado: 16 de febrero de 2019

DOI: IO.I 344/ANPSIC2OI9.49.3

ISSN: 0066-5126 | (C) 2019 Universitat de Barcelona. All rights reserved.

\title{
Influencia de la formación musical en el rendimiento académico: una revisión bibliográfica
}

\section{Cristina Álvaro-Mora Miguel Ángel Serrano-Rosa}

\section{Resumen}

La formación musical ha generado un reciente interés en el campo de la educación y la psicología con el aumento de la investigación desde la neurociencia, la cual demuestra sus efectos positivos en el desarrollo tanto a nivel cognitivo como de rendimiento académico. El objetivo de esta revisión es conocer los procesos cognitivos que explican la relación entre la formación musical y el rendimiento académico. Para ello, sintetizamos un conjunto de estudios mediante un procedimiento estructurado en tres pasos: búsqueda inicial, sistemática y manual. Los resultados muestran cómo los alumnos con formación musical presentan mejor memoria verbal, funciones ejecutivas, atención selectiva y plasticidad cerebral. Estos datos sugieren que el entrenamiento musical durante el período escolar puede favorecer el rendimiento académico. El grado de estos cambios parece ser precedido por las diferencias individuales preexistentes en los alumnos, así como en el tiempo de entrenamiento, entre otros factores. Concluimos que la formación musical produce efectos positivos directos sobre la diferenciación neuroanatómica, habilidades cognitivas y, a su vez, un aumento del logro y rendimiento académico.

\section{Pallabras clave}

Logro académico, Funciones ejecutivas, Entrenamiento musical, Niños, Adolescentes

\section{Influence of musical training on academic performance: a bibliographical review}

\section{Abstract}

Music education has gained recent interest in the field of education and psychology with an increase of neuroscientific research, which demonstrates its positive effects on cognitive development and academic performance. The objective of this review is to look at the different cognitive processes that explain the relationship between musical training 
and academic performance. We synthesized a set of studies through a structured procedure in three steps: initial, systematic and manual research. The results show how students with musical training have better verbal memory, executive functions, selective attention and brain plasticity. These data suggest that musical training during the school period may favor academic performance. The degree of these changes seems to be preceded by pre-existing individual differences in students, as well as in training time, among other factors. We conclude that musical training produces direct positive effects on neuroanatomical differentiation, cognitive abilities and, at the same time, an increase in achievement and academic performance.

\section{Keywords}

Academic achievement, executive functions, music training, child, adolescent.

\section{INTRODUCCIÓN}

r recuentemente se debate sobre la educación que los niños y adolescentes están recibiendo en las aulas, y de si esta es la más adecuada. Si se pregunta a pie de calle, surge una amplia variedad de opiniones, basada en diferentes orientaciones y creencias, sobre el tipo de formación que los alumnos deberían tener y, dada la situación actual, también sobre la gran oferta de actividades educativas complementarias como estudiar un idioma, realizar un deporte o recibir formación musical, siendo esta última en la que se ha centrado este estudio. La formación musical está ampliamente contextualizada por la cultura, otorgándole múltiples puntos de vista. Se la relaciona con una formación muy específica, que conlleva mucho tiempo y esfuerzo, y que a su vez no complementa ni refuerza los estudios obligatorios sino que, al contrario, produce efectos negativos en el rendimiento académico de los niños y, a la larga, una menor formación para el mundo laboral, la cual es, por lo general, la meta de toda formación en la sociedad actual. Por otro lado, también se entiende esta formación como algo positivo, y se asocia con aportaciones a nivel cognitivo y organizativo, así como con un rasgo de identidad y socialización, a la par que se considera una actividad de ocio.

Al realizar una pequeña investigación en la documentación científica actual, es fácil encontrar estudios donde la investigación en psicología y neurociencia comienza a preguntarse qué ocurre con estos niños y adolescentes que estudian música (Habibi, Damasio, Ilari, Sachs y Damasio, 2018; Habibi y cols., 2017; Moreno y cols., 2008). Los resultados, en su mayor parte positivos, demuestran que la formación musical en niños de edad escolar se asocia con una mejora de habilidades verbales y razonamiento general (Herrero y Carriedo, 2018; Jaschke, Honing y Scherder, 2018; Roden, Kreutz y Bongard, 2012). También es cierto que la ciencia avanza despacio y aún es difícil saber a qué nivel se producen estos cambios y la causa de los mismos (Miendlarzewska y cols., 2014).
Como se ha afirmado anteriormente, la visión de la formación queda orientada en muchos casos hacia la preparación y éxito en el mundo laboral. En este contexto, los investigadores comienzan poco a poco a interesarse por lo que ocurre a los estudiantes que tienen un entrenamiento musical y cómo este influye en su desarrollo futuro, tanto a nivel cognitivo como a nivel funcional. Así, existe evidencia empírica que relaciona los efectos del entrenamiento musical de forma activa con el desarrollo intelectual, social y personal de estos niños y adolescentes (Schellenberg, 2011; Hallam, 2010; Schellenberg, 2004).

El desarrollo a la vida adulta se gesta desde el inicio de nuestras vidas. Nuestros rasgos de personalidad, nuestro entorno de crianza, cultura o educación moldean quiénes somos y quiénes seremos en un futuro. Hallam (2010) realizó también una aportación en esta orientación al afirmar que la formación musical produce desarrollo a nivel cognitivo y un impacto a diferentes niveles como el desarrollo del lenguaje, alfabetización aritmética, inteligencia, logro, creatividad, coordinación motora fina, concentración, autoconfianza, sensibilidad emocional, habilidades sociales, trabajo en equipo, autodisciplina y relajación. La mayoría de estas habilidades podemos encontrarlas actualmente dentro de las programaciones educativas, como competencias que se deben superar y/o adquirir dentro de los centros educativos. Desde esta nueva perspectiva y dado que la introducción al mundo laboral se realiza al finalizar la etapa académica, estos argumentos justifican la influencia de la formación musical dentro del período de formación académica.

Este efecto del entrenamiento musical ha sido investigado recientemente. Holochwost y cols., (2017) realizaron un estudio donde se demostró que la educación musical produce efectos positivos en el rendimiento escolar y las funciones ejecutivas de 265 estudiantes escolares, con una media de edad de 10,2 años, que formaban parte de un programa de educación musical. Estos efectos se observaron de manera significativa en asignaturas como 
inglés, arte y matemáticas. Además, mostraron cómo la formación musical influye indirectamente en el rendimiento dentro de la formación reglada. Siguiendo la misma línea, Dos Santos-Luiz (2016) presentó un estudio en el cual resultó reflejada la asociación positiva entre la formación musical y el rendimiento académico. En este caso se realizó un estudio longitudinal que concluyó que los alumnos con estudios musicales no solo obtenían una mejor posición académica en matemáticas, ciencias naturales, historia y geografía, sino que también presentaban unos resultados académicos más consistentes durante todo el estudio longitudinal. Esta visión sobre la formación musical y su incidencia en el desarrollo escolar cuenta con muchos años intuyéndose en el terreno de la investigación en la psicología y la neurociencia. Así, de confirmarse una influencia significativa de la formación musical sobre el rendimiento académico y la diferenciación de los alumnos en habilidades cognitivas y anatomía cerebral, podría conducir a un cambio en la visión actual sobre el tipo de educación que los niños deben cursar.

Es, por tanto, una de estas nuevas áreas de estudio de donde parte esta investigación; concretamente en el nexo entre la psicología y la música vistas desde el concepto del rendimiento académico. Consideramos que se hace necesario el estudio de estas tres disciplinas en conjunto por la riqueza que pueden aportarse entre sí y la influencia mutua en la práctica. Así, los investigadores han comenzado a realizar estudios relacionando estas tres disciplinas, orientando y focalizando cada una de estas investigaciones hacia variables y factores diferentes. Pero parece que una variable se prioriza y analiza en relación con los mejores resultados académicos: las funciones ejecutivas. Las «funt ciones ejecutivas, también conocidas como control cognitivo, son un conjunto de procesos descendentes que participan en la planificación y regulación de la cognición y el comportamiento (...) La mayoría de los modelos de funciones ejecutivas postulan tres componentes relacionados pero separables: control inhibitorio, flexibilidad cognitiva y actualización de la memoria de trabajo (...) El control inhibitorio requiere el control de los propios pensamientos o el comportamiento para anular una respuesta potente. Por otro lado, la flexibilidad cognitiva requiere esfuerzo para cambiar las perspectivas o cambiar entre las demandas de tareas. Por último, la actualización de la memoria de trabajo requiere un esfuerzo para mantener, agregar y eliminar elementos de la memoria. Estas funciones ejecutivas se desarrollan durante la adolescencia y se pueden mejorar con la práctica (...)» (Okada y cols., 2017, p.1)

A partir de toda esta información, las cuestiones que se plantean como objetivo de esta revisión son las siguientes: ¿por qué presentan mejor rendimiento académico aquellos alumnos y alumnas con estudios musicales? ¿En qué funciones cognitivas destacan estos estudiantes que puedan ser las responsables de este mejor rendimiento? ¿Tienen algún correlato neurofisiológico estas funciones ejecutivas? En consecuencia, el objetivo de este estudio es conocer los diversos procesos cognitivos que explican la relación entre la formación musical y el rendimiento académico, mediante una revisión temática de las investigaciones orientadas hacia la comparación del rendimiento académico y los cambios a nivel cognitivo y neuroanatómico en niños de edad escolar y adolescentes entrenados y no entrenados musicalmente. La metodología en esta investigación será abordada desde una revisión bibliográfica de las investigaciones publicadas en esta línea de estudio en diferentes bases de datos. Es mucha y creciente la literatura que ya refiere esta comparativa e indaga sobre el porqué de esta diferenciación. Si se confirmase sólidamente que las personas con formación musical presentan un mayor rendimiento que los no músicos, podría provocar un cambio significativo en el enfoque pedagógico y educativo.

\section{METODOLOGÍA}

La metodología realizada en la investigación se ha estructurado en función de las directrices de la declaración PRISMA (Moher et al., (2009) y Urrútia y Bonfill (2013). Seguidamente se presenta el proceso llevado a cabo mediante su organización en tres puntos diferenciados:

En primer lugar, se ha realizado la búsqueda inicial, la cual nos proporciona el volumen de publicaciones sobre el tema estudiado y las fuentes más relevantes para realizar la siguiente búsqueda. Para ello se seleccionaron varias fuentes documentales: Google Académico, Scopus, ProQuest, Web of Science y Pubmed. Todas las búsquedas se realizaron por medio de bases de datos en dos idiomas, inglés y español, dado el interés en encontrar artículos publicados con gran validez, fiabilidad y lo más actualizados posibles. Estas bases de datos fueron seleccionadas por su alto contenido en publicaciones del ámbito de la psicología y la cantidad de estudios publicados en línea con nuestra temática. Estos documentos fueron seleccionados en el período que comprende de noviembre de 2017 a marzo de 2018, siendo el 20 de este último mes la fecha de la última búsqueda realizada.

Las búsquedas iniciales se realizaron introduciendo la combinación de los siguientes términos: «achievement» $y$ «music training». Sin embargo, hubo que ampliar el número de términos de búsqueda, dado que el uso único de estos dos términos no generaba la suficiente cantidad de publicaciones para realizar un estudio. Así, se seleccionaron las siguientes palabras clave: «academic achievement», «executive functions», «music», «music education», «music lessons», «musicians», «child» y «adolescent», las cuales se introdujeron en los buscadores utilizando operadores boleanos (AND y OR), para obtener todas las referencias publicadas. Las consecuencias de ampliar las palabras clave nos proporcionaron, como habíamos previsto, un mayor número de publicaciones, que incluían información relevante sobre nuestro interés y orientó el siguiente paso. 
Tabla 1. Criterios de inclusión y exclusión

\begin{tabular}{l|l|l}
\multirow{2}{*}{ Eriterio } & Inclusión & Exclusión \\
\hline \multirow{2}{*}{ Tipo de estudio } & Rango de edad de 6-18 años. & Menores de 6 \\
\cline { 2 - 3 } Período temporal & Estudios experimentales & Mayores de 18 años \\
\hline \multirow{2}{*}{ Temática } & $\begin{array}{l}\text { Comparación de estudiantes de música y no estudiantes } \\
\text { de música, y su relación con las funciones ejecutivas y/o } \\
\text { el rendimiento académico }\end{array}$ & $\begin{array}{l}\text { Participantes no diferenciados en entre- } \\
\text { namiento musical y no entrenamiento } \\
\text { musical }\end{array}$ \\
\hline
\end{tabular}

En segundo lugar, realizamos la búsqueda sistemática, la cual ha consistido en, una vez delimitados los criterios de inclusión y exclusión de nuestra orientación temática, llevar a cabo una búsqueda en las bases de datos seleccionadas usando dichos términos.

El tema de esta investigación se fundamenta en dos conceptos clave, el rendimiento escolar de alumnos y alumnas con o sin entrenamiento musical, y la diferenciación que ambos grupos presentan en cuanto a las capacidades de las funciones ejecutivas. Por ello, teniendo en cuenta la finalidad de realizar una exploración filtrada y orientada hacia nuestro objetivo, se establecieron los siguientes criterios de inclusión:

- El rango de edad comprendido entre la edad de inicio escolar hasta la finalización de estudios preuniversitarios, 6-18 ańos. Esta concreción se justifica al ser el período en el que se dan paralelamente los estudios obligatorios y los estudios musicales y por su relevancia como período de desarrollo cognitivo relevante. En la bibliografía se admitieron aquellos estudios de una muestra doble de 6-18 años y otra muestra de 18-35 años por requerimientos de su investigación.

- Otro criterio establecido ha sido la elección de estut dios experimentales, dado que aportan información contrastada mediante pruebas estandarizadas con fiabilidad y validez.

- Se incluyeron también aquellas investigaciones publicadas entre los años 2000 y 2018, al considerarse investigaciones actualizadas.

- De igual modo, se consideraron aquellos artículos que investigaron dentro del campo temático, hicieron aportaciones en el marco de la comparativa de estudiantes de música y no estudiantes de música, y los relacionaron con las funciones ejecutivas y/o el rendimiento académico.

Por el contrario, los criterios de exclusión han dejado fuera a las siguientes investigaciones:

- Las realizadas en adultos mayores de 18 años, considerando la posibilidad de que el estudio de música deje de realizarse paralelamente a otra formación y/o se produzca un abandono de estos o una exclusividad de los mismos. Y aquellos con una muestra de edad menor de 6 años al no ser contrastados con la variable del rendimiento académico.

- Aquellos estudios que no se hayan realizado bajo experimentación, dado que no son estudios científicos validados mediante pruebas estadísticas y estandarizadas. Descartamos las publicaciones anteriores al año 2000, dada su antigüedad y probable desactualización.

- Por último, se rechazaron aquellos estudios donde la muestra de participantes no está delimitada entre participantes con entrenamiento musical y no entrenamiento musical pese a que incluyeran variables de rendimiento académico y funciones ejecutivas.

En la tabla 1 del anexo se muestran resumidos los criterios de inclusión y exclusión delimitados para nuestro procedimiento.

Tras la delimitación de estas fuentes, se procedió a la descripción de la estrategia y la identificación de los documentos que cumplían los criterios establecidos de inclusión y exclusión. Se seleccionaron un total de 51 artículos con estas características. En la tabla 2 se encuentran reflejados el número de artículos aceptados y excluidos, clasificados por tipo de búsqueda y base de datos.

Por último, se realizó una búsqueda manual seleccionando los artículos que se han considerado relevantes y revisando la bibliografía de estos para identificar estudios adicionales válidos. Se seleccionaron aquellos artículos que

Tabla 2. Clasificación de los resultados de la búsqueda

\begin{tabular}{l|l|l}
\hline Bases de datos & Incluidos & Excluidos \\
\hline Google Académico & 10 & 4 \\
\hline Scopus & 4 & 2 \\
\hline ProQuest & 11 & 5 \\
\hline Web of Science & 2 & 0 \\
\hline Pubmed & 5 & 6 \\
\hline Búsqueda Manual & 2 & 0 \\
\hline Total & $\mathbf{3 4}$ & $\mathbf{1 7}$
\end{tabular}


Figura 1. Diagrama de flujo PRISMA en 4 niveles

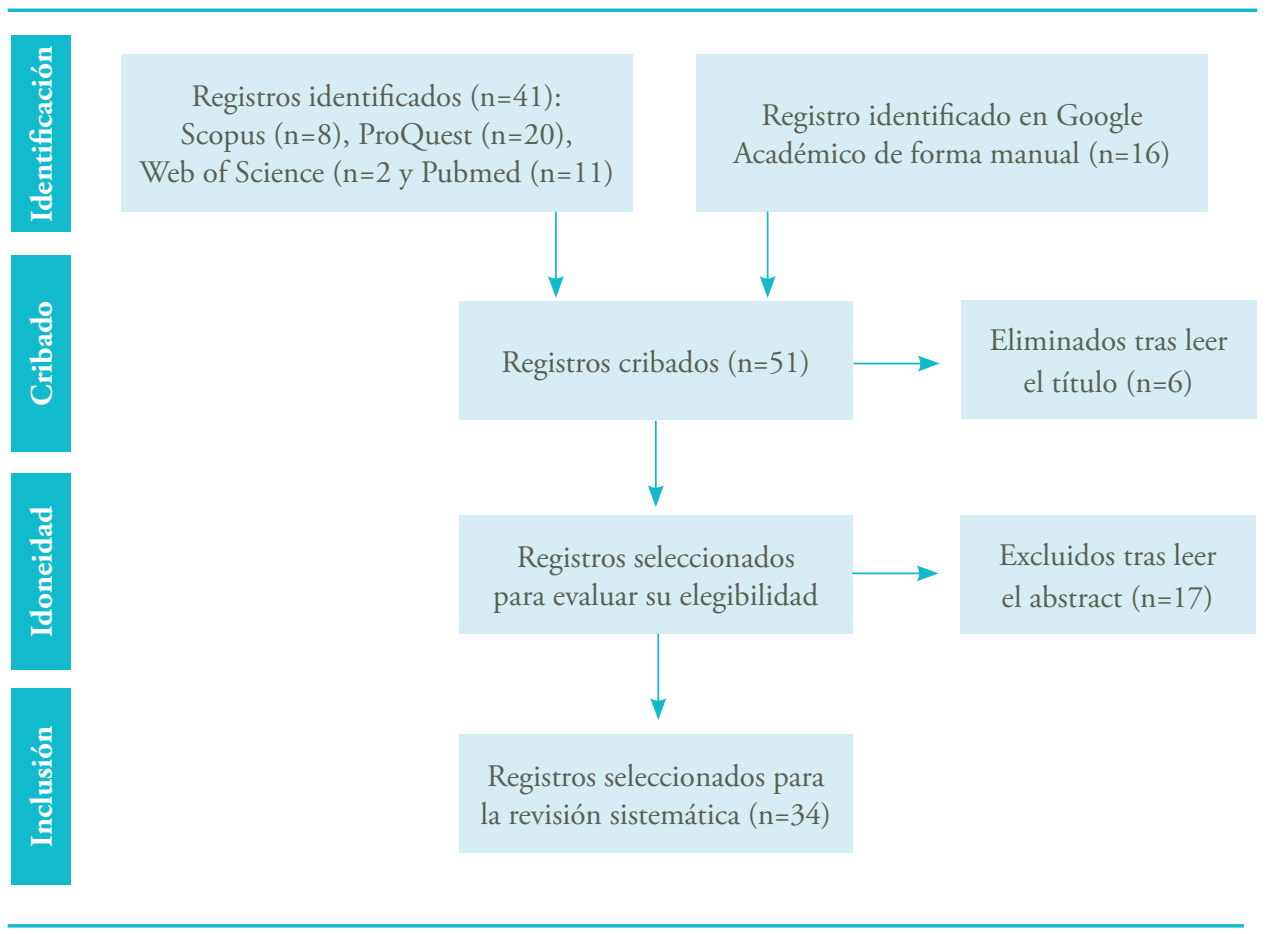

cumplieran los requisitos limitados por esta investigación, y para ello utilizamos de nuevo Google Académico incluyendo las diferentes combinaciones de nuestros términos de búsqueda, con la finalidad de no dejar excluido ningún artículo relevante. Mediante este proceso incluimos finalmente dos nuevos artículos (véase figura 1).

\section{ANÁLISIS PRELIMINAR DE LA BIBLIOGRAFÍA SELECCIONADA}

Los principales resultados de este estudio quedan reflejados en la tabla 3. Todos ellos incluyen estudios con participantes de edades comprendidas entre los 6-18 años, con excepción de tres que incluyen dos muestras: una dentro de nuestros criterios de inclusión y otra formada por un rango de edad comprendido entre los 18 años y los 35 ańos (Zuk, Benjamin, Kenyon y Gaab, 2014; Kathleen y cols., 2013; Stoeber y Eismann, 2007). La mayoría de los artículos emplearon ambos géneros, exceptuando dos, que solo tomaron una muestra de varones (Cogo-Moreira, Clara, Ploubidis y Jair, 2013; Ho, Cheung y Chan, 2013), y el tamańo de la muestra varió entre 32 participantes (Moreno et al., 2008) hasta 45.000 (Southgate y Roscigno, 2009).

Los artículos revisados han resultado estar todos enfocados hacia una orientación similar a la expuesta dentro de nuestros objetivos y han generado una gran variedad de enfoques y heterogeneidad dentro de la indagación en la formación musical. En general, este entrenamiento consiste en actividades de instrucción musical, tanto a ni- vel individual como grupal y canto (Costa-Giomi, 2016; Hallam y Rogers, 2016; Helmrich, 2010). Uno de estos estudios incluye el enfoque de comparación de estos grupos con otros con entrenamiento deportivo o formación en materias específicas como ciencias naturales, inglesas y matemáticas (Roden et al., 2012).

\section{Resultados}

Esta revisión analizó la evidencia de 34 estudios, que tratan sobre la influencia de la formación musical en el rendimiento académico. Estos incluyen tres áreas de desarrollo, que son el rendimiento académico, la cognición y la neuroanatomía. Se expondrán los resultados extraídos en función de dichos apartados.

\section{Música y rendimiento académico}

Respecto al rendimiento académico, las 11 investigaciones encontradas sugieren que la formación musical no imposibilita ni interfiere en el logro académico, sino que, al contrario, fomenta la excelencia académica (Holochwost y cols., 2017; Ribeiro y Santos, 2017; Degé y Schwarzer, 2017; Costa-Giomi, 2016; Dos Santos-Luiz, 2016; Hallam y Rogers, 2016; Yang y cols., 2014; Cogo-Moreira y cols., 2013; Helmrich y cols., 2010; Southgate y Roscigno 2009; Gouzouasis y cols., 2007). Estas investigaciones recalcan la obtención de puntuaciones académicas más altas en asignaturas como matemáticas, segunda lengua y ciencias naturales, de aquellos participantes que sí tenían un entrenamiento musical (Ribeiro y Santos, 2017; Holochwost y cols., 2017; Dos Santos-Luiz, 2016; Yang 
Tabla 3. Lista de artículos revisados incluyendo autores, año, número de participantes y resultados principales

\begin{tabular}{|c|c|c|c|c|}
\hline Autores & Año & Participantes & Variables & Resultados \\
\hline $\begin{array}{l}\text { Herrero, L. } \\
\text { Carriedo, N. }\end{array}$ & 2018 & $\begin{array}{l}138 \text { niños } \\
69 \text { músicos: } 37 \text { niños } \\
(\mathrm{R}=10-11) \text { y } 32 \text { adoles- } \\
\text { centes }(\mathrm{R}=15-16) \\
69 \text { no músicos: } 37 \text { niños } \\
(\mathrm{R}=10-11) \text { y } 32 \text { adoles- } \\
\text { centes }(\mathrm{R}=15-16)\end{array}$ & $\begin{array}{l}\text { Función ejecutiva } \\
\text { Entrenamiento } \\
\text { musical }\end{array}$ & $\begin{array}{l}\text { Músicos: mejores puntuaciones } \\
\text { en mantenimiento y en los procesos } \\
\text { inhibitorios (resistencia a la interferen- } \\
\text { cia proactiva) }\end{array}$ \\
\hline $\begin{array}{l}\text { Jaschke, Artur C. } \\
\text { Honing, Henkjan } \\
\text { Scherder, Erik J. A. }\end{array}$ & 2018 & $\begin{array}{l}147 \text { niños }(M=6.4) \\
\cdot 2 \text { grupos musicales: } \\
42 \text { niños en un grupo } \\
\text { y } 37 \text { en otro grupo } \\
\cdot 1 \text { grupo de artes visuales } \\
\text { (29 niños) } \\
\cdot 1 \text { grupo de control } \\
\text { (37 niños) }\end{array}$ & $\begin{array}{l}\text { Inteligencia verbal } \\
\text { Funciones ejecutivas } \\
\text { - Rendimiento acadé- } \\
\text { mico }\end{array}$ & $\begin{array}{l}\text { El grupo de artes visuales: mejor } \\
\text { en tareas de memoria visoespacial. } \\
\text { Grupo músicos: mejor puntuación en } \\
\text { inhibición, planificación e inteligencia } \\
\text { verbal. Efecto de transferencia desde la } \\
\text { subfunción ejecutiva hasta los puntajes } \\
\text { de rendimiento académico }\end{array}$ \\
\hline $\begin{array}{l}\text { Habibi, Assal } \\
\text { Damasio, Antonio } \\
\text { Ilari, Beatriz } \\
\text { Elliott Sachs } \\
\text { Matthew Damasio, } \\
\text { Hanna }\end{array}$ & 2018 & $\begin{array}{l}68 \text { niños }(\mathrm{R}=6-7) \\
\cdot 21 \text { músicos } \\
\cdot 23 \text { grupo deportivo } \\
\cdot 24 \text { grupo control }\end{array}$ & $\begin{array}{l}\text { - Estatus socioeconó- } \\
\text { mico } \\
\text {. Inteligencia (QI) } \\
\text { · Neuroanatomía cere- } \\
\text { bral (fMRI) }\end{array}$ & $\begin{array}{l}\text { Músicos: alta puntuación en habili- } \\
\text { dades auditivas y mostraban cambios } \\
\text { cerebrales relacionados en las áreas } \\
\text { responsables de la audición. } \\
\text { Mayor activación neuronal en tarea } \\
\text { de inhibición cognitiva } \\
\text { El entrenamiento musical induce } \\
\text { cambios cerebrales y comportamenta- } \\
\text { les en los niños, y esos cambios no son } \\
\text { atribuibles a rasgos biológicos preexis- } \\
\text { tentes }\end{array}$ \\
\hline $\begin{array}{l}\text { Habibi, Assal } \\
\text { Damasio, Antonio } \\
\text { Ilari, Beatriz } \\
\text { Veiga, Ryan } \\
\text { Joshi, Anand A. } \\
\text { Leahy, Richard M. } \\
\text { Haldar, Justin P. } \\
\text { Varadarajan, Divya } \\
\text { Bhushan, Chitresh } \\
\text { Damasio, Hanna }\end{array}$ & 2017 & $\begin{array}{l}56 \text { niños }(\mathrm{R}=6-7) \\
\cdot 18 \text { músicos }(5 \text { mujeres } \\
\text { y } 13 \text { varones. } \mathrm{M}=6.64) \\
\cdot 18 \text { grupo de control } \\
\text { deportivo }(10 \text { mujeres } \\
\text { y } 8 \text { varones } \mathrm{M}=7.04) \\
\cdot 20 \text { no músicos } \\
(8 \text { mujeres y } 12 \text { varones. } \\
\mathrm{M}=5.85) .\end{array}$ & $\begin{array}{l}\text { - Inteligencia }(\mathrm{QI}) \\
\cdot \text { Neuroanatomía } \\
(\mathrm{fMRI}) \\
\cdot \text { Estatus socioeconó- } \\
\text { mico }\end{array}$ & $\begin{array}{l}\text { A los } 2 \text { años de entrenamiento mu- } \\
\text { sical: diferente tasa de maduración y } \\
\text { espesor cortical. También más alta ani- } \\
\text { sotropía fraccional en el cuerpo calloso } \\
\text { Conclusión: el entrenamiento musical } \\
\text { induce cambios macro- y microestruc- } \\
\text { turales en el cerebro, y esos cambios } \\
\text { no son atribuibles a rasgos biológicos } \\
\text { preexistentes }\end{array}$ \\
\hline $\begin{array}{l}\text { Joret, Marie-Eve } \\
\text { Germeys, Filip } \\
\text { Gidron, Yori }\end{array}$ & 2017 & $\begin{array}{l}63 \text { niños }(\mathrm{M}=10.44 ; \\
\mathrm{R}=9.5-11.5) \\
\cdot 35 \text { varones y } 28 \text { mujeres } \\
\cdot 32 \text { músicos y } 31 \text { no } \\
\text { músicos }\end{array}$ & $\begin{array}{l}\text { - Efecto de congruencia } \\
\text { - Funciones ejecutivas } \\
\text { - Bilingüismo } \\
\text { - Estado socioeconó- } \\
\text { mico } \\
\text { - Pedagogía musical } \\
\text { - Tiempo de formación } \\
\text { - Inteligencia }\end{array}$ & $\begin{array}{l}\text { Músicos: magnitud reducida del efecto } \\
\text { de congruencia } \\
\text { El entrenamiento musical está asociado } \\
\text { con el control inhibitorio cognitivo }\end{array}$ \\
\hline $\begin{array}{l}\text { Mandikal Vasuki } \\
\text { Pragati Rao } \\
\text { Sharma, Mridula } \\
\text { Ibrahim, Ronny } \\
\text { Arciuli, Joanne }\end{array}$ & 2017 & $\begin{array}{l}50 \text { niños }(\mathrm{R}=9-11) \\
\cdot 25 \text { músicos }(14 \text { mujeres, } \\
11 \text { varones; } \mathrm{M}=10,5) ; \\
\cdot 25 \text { nińos sin entrena- } \\
\text { miento musical } \\
(9 \text { mujeres y } 16 \text { varones; } \\
M=10,1)\end{array}$ & $\begin{array}{l}\text { Discriminación meló- } \\
\text { dica y rítmica } \\
\text { - Aprendizaje auditivo } \\
\text {. Conducta } \\
\text {. Entrenamiento } \\
\text { musical }\end{array}$ & $\begin{array}{l}\text { Músicos: mejor discriminación de } \\
\text { melodías, ritmo, frecuencia y aprendi- } \\
\text { zaje auditivo } \\
\text { Este entrenamiento se asoció con el } \\
\text { rendimiento en las tareas de aprendiza- } \\
\text { je de la conducta auditiva y visual } \\
\text { El entrenamiento musical se asocia con } \\
\text { una mejor codificación de los estímu- } \\
\text { los visuales y auditivos }\end{array}$ \\
\hline
\end{tabular}




\begin{tabular}{|c|c|c|c|c|}
\hline Autores & Año & Participantes & Variables & Resultados \\
\hline $\begin{array}{l}\text { Ribeiro, F. S. } \\
\text { Santos, F. H. }\end{array}$ & 2017 & $\begin{array}{l}223 \text { niños }(M=8) \\
\text {. Grupo 1: } 26 \text { niños sin } \\
\text { déficit (5 mujeres y } 21 \\
\text { varones) } \\
\text { - Grupo 2: } 20 \text { niños con } \\
\text { bajo rendimiento ( } 6 \\
\text { mujeres y } 14 \text { varones) } \\
\text {. Grupo control: } 177 \\
\text { niños }\end{array}$ & $\begin{array}{l}\text { Entrenamiento } \\
\text { musical } \\
\text {. Rendimiento en } \\
\text { matemáticas }\end{array}$ & $\begin{array}{l}\text { En el estudio post disminuyeron el nú- } \\
\text { mero de niños con bajas puntuaciones } \\
\text { en matemáticas } \\
\text { El entrenamiento musical parece ser } \\
\text { un recurso útil para la mejora de niños } \\
\text { con bajo rendimiento en matemáticas }\end{array}$ \\
\hline $\begin{array}{l}\text { Sachs, Matthew } \\
\text { Kaplan, Jonas } \\
\text { Der Sarkissian, Alissa } \\
\text { Habibi, Assal }\end{array}$ & 2017 & $\begin{array}{l}44 \text { niños }(\mathrm{M}=8,67) \\
\cdot 14 \text { formación musical } \\
\text { continua } \\
\cdot 13 \text { grupo deportivo }(\mathrm{M} \\
=8,85) \\
\cdot 17 \text { grupo control }(\mathrm{M}= \\
9,05) .\end{array}$ & $\begin{array}{l}\cdot \text { Entrenamiento } \\
\text { musical } \\
\cdot \text { Estatus socioeconó- } \\
\text { mico } \\
\text { · Funciones ejecutivas } \\
\cdot \text { Respuestas neuronales } \\
\text { (fMRI) }\end{array}$ & $\begin{array}{l}\text { El entrenamiento musical se asocia con } \\
\text { cambios en la red de control cognitivo } \\
\text { en el cerebro, incluso en ausencia de } \\
\text { cambio en el desempeńo conductual }\end{array}$ \\
\hline $\begin{array}{l}\text { Rose, Dawn } \\
\text { Jones Bartoli, Alice; } \\
\text { Heaton, Pamela }\end{array}$ & 2017 & $\begin{array}{l}38 \text { niños }(21 \text { mujeres } \\
\text { y } 17 \text { varones })(\mathrm{R}=7-9)\end{array}$ & $\begin{array}{l}\text { Inteligencia } \\
\text { Memoria } \\
\text { Comportamiento } \\
\text { socioemocional } \\
\text { - Motricidad e integra- } \\
\text { ción visual-motora } \\
\text { pre- y post- }\end{array}$ & $\begin{array}{l}\text { Asociación significativa entre la aptitud } \\
\text { musical y la inteligencia en general } \\
\text { Aumento significativo del coeficiente } \\
\text { intelectual en los músicos y motricidad } \\
\text { gruesa } \\
\text { No se encontraron efectos para la me- } \\
\text { moria, integración visual motora } \\
\text { o el comportamiento socioemocional }\end{array}$ \\
\hline $\begin{array}{l}\text { Holochwost, Steven J. } \\
\text { Propper, Cathi B. } \\
\text { Wolf, Dennie Palmer } \\
\text { Willoughby, Michael T. } \\
\text { Fisher, Kelly R. } \\
\text { Kolacz, Jacek } \\
\text { Volpe, Vanessa V. } \\
\text { Jaffee, Sara R. }\end{array}$ & 2017 & $\begin{array}{l}265 \text { niños }(M=10,2) \\
\cdot 135 \text { músicos } \\
\cdot 130 \text { grupo control }\end{array}$ & $\begin{array}{l}\text { Rendimiento acadé- } \\
\text { mico } \\
\text {. Funciones ejecutivas } \\
\text {. Características demo- } \\
\text { gráficas }\end{array}$ & $\begin{array}{l}\text { Con entrenamiento musical: obtu- } \\
\text { vieron una puntuación más alta en } \\
\text { rendimiento académico (inglés, arte } \\
\text { y matemáticas) funciones ejecutivas y } \\
\text { memoria a corto plazo }\end{array}$ \\
\hline $\begin{array}{l}\text { Alemán, Xiomara } \\
\text { Duryea, Suzanne } \\
\text { Guerra, Nancy G. } \\
\text { McEwan, Patrick J. } \\
\text { Muñoz, Rodrigo } \\
\text { Stampini, Marco } \\
\text { Williamson, Ariel A. }\end{array}$ & 2017 & 2.914 niños. $\mathrm{R}=6-14$ & $\begin{array}{l}\text { - Autorregulación } \\
\text { Cognición } \\
\text { - Comportamiento } \\
\text { - Conexiones proso- } \\
\text { ciales } \\
\text {. Entrenamiento } \\
\text { musical }\end{array}$ & $\begin{array}{l}\text { Los niños más expuestos a las lecciones } \\
\text { de música presentan mejor autocon- } \\
\text { trol y una reducción de dificultades } \\
\text { conductuales } \\
\text { Mayor efecto en los niños clasificados } \\
\text { como subgrupo vulnerable }\end{array}$ \\
\hline $\begin{array}{l}\text { Degé, Franziska } \\
\text { Schwarzer, Gudrun }\end{array}$ & 2017 & $\begin{array}{l}30 \text { niños ( } 11 \text { varones } \\
\text { y } 19 \text { mujeres) } \mathrm{R}=9-11 \\
\cdot 13 \text { con entrenamiento } \\
\text { musical } \\
\cdot 17 \text { sin entrenamiento } \\
\text { musical }\end{array}$ & $\begin{array}{l}\text { - Autoconcepto acadé- } \\
\text { mico } \\
\cdot \text { Actividades extraesco- } \\
\text { lares Inteligencia (CI) } \\
\text { - Aptitud musical } \\
\text { - Motivación }\end{array}$ & $\begin{array}{l}\text { No diferencias en variables de confu- } \\
\text { sión } \\
\text { Diferencias significativas en el auto- } \\
\text { concepto académico que era más alto } \\
\text { en los niños del grupo con entrena- } \\
\text { miento musical }\end{array}$ \\
\hline $\begin{array}{l}\text { Costa-Giomi, Eu- } \\
\text { ginia }\end{array}$ & 2016 & $\begin{array}{l}117 \text { participantes }(58 \\
\text { mujeres y } 59 \text { varones })(\mathrm{M} \\
=9) \\
.63 \text { músicos } \\
.54 \text { no músicos }\end{array}$ & $\begin{array}{l}\cdot \text { Autoestima } \\
\cdot \text { Rendimiento acadé- } \\
\text { mico } \\
\cdot \text { Habilidades cogni- } \\
\text { tivas } \\
\cdot \text { Habilidades musicales } \\
\cdot \text { Competencia motora } \\
\cdot \text { Estado socioeconó- } \\
\text { mico }\end{array}$ & $\begin{array}{l}\text { Grupo con instrucción de piano: } \\
\text { efecto positivo en la autoestima de los } \\
\text { niños } \\
\text { No diferencias significativas en rendi- } \\
\text { miento académico en matemáticas y } \\
\text { lenguaje medido en los exámenes es- } \\
\text { tandarizados y clasificaciones escolares }\end{array}$ \\
\hline
\end{tabular}




\begin{tabular}{|c|c|c|c|c|}
\hline Autores & Año & Participantes & Variables & Resultados \\
\hline $\begin{array}{l}\text { Carlos dos San- } \\
\text { tos-Luiz }\end{array}$ & 2016 & $\begin{array}{l}110 \text { participantes: } \\
.62 \text { músicos ( } 17 \text { varones } \\
\text { y } 45 \text { mujeres. } \\
\mathrm{M}=11,74) \\
.48 \text { no músicos } \\
(26 \text { varones y } 22 \text { muje- } \\
\text { res. } \mathrm{M}=11,75)\end{array}$ & $\begin{array}{l}\text { - Estado socioeconó- } \\
\text { mico } \\
\text { - Inteligencia } \\
\text { - Motivación } \\
\text { - Rendimiento acadé- } \\
\text { mico }\end{array}$ & $\begin{array}{l}\text { Músicos: obtienen mejores resultados } \\
\text { académicos. Estos mantuvieron una } \\
\text { posición académica mejor y más con- } \\
\text { sistente durante todo el estudio } \\
\text { Asociación positiva entre el aprendizaje } \\
\text { musical y el rendimiento académico }\end{array}$ \\
\hline $\begin{array}{l}\text { Hallam, Susan } \\
\text { Rogers, Kevin }\end{array}$ & 2016 & $\begin{array}{l}608 \text { niños }(\mathrm{R}=11-16) . \\
\cdot 115 \text { tocaban un instru- } \\
\text { mento musical }\end{array}$ & $\begin{array}{l}\text { Entrenamiento } \\
\text { musical } \\
\text { - Tiempo de entrena- } \\
\text { miento musical } \\
\text { - Rendimiento acadé- } \\
\text { mico }\end{array}$ & $\begin{array}{l}\text { Con entrenamiento musical: mayor } \\
\text { progreso y mejores resultados acadé- } \\
\text { micos. Mejores resultados dentro del } \\
\text { grupo de músicos de aquellos que } \\
\text { llevaban tocando más tiempo }\end{array}$ \\
\hline $\begin{array}{l}\text { Roden, Ingo } \\
\text { Zepf, Florian D. } \\
\text { Kreutz, Gunter } \\
\text { Grube, Dietmar } \\
\text { Bongard, Stephan }\end{array}$ & 2016 & $\begin{array}{l}34 \text { niños ( } 15 \text { varones y } 19 \\
\text { mujeres) }(\mathrm{R}=7-8) \\
\text { - Músicos: } 14 \text { niños } \\
\text { - Grupo control: } 20 \text { niños } \\
\text { formados en ciencias } \\
\text { naturales }\end{array}$ & $\begin{array}{l}\text { Entrenamiento } \\
\text { musical } \\
\text { - Respuesta de estrés }\end{array}$ & $\begin{array}{l}\text { Las medidas fisiológicas no resultaron } \\
\text { significativamente diferentes } \\
\text { El entrenamiento musical modula } \\
\text { positivamente la conducta agresiva } \\
\text { reactiva en los niños }\end{array}$ \\
\hline $\begin{array}{l}\text { Kathleen A. Corrigall } \\
\text { E. Glenn Schellen- } \\
\text { berg }\end{array}$ & 2015 & $\begin{array}{l}170 \text { Niños ( } 88 \text { mujeres y } \\
82 \text { varones) }(\mathrm{R}=7-9) \\
\text { Con diferentes niveles de } \\
\text { entrenamiento musical }\end{array}$ & $\begin{array}{l}\cdot \text { Inteligencia } \\
\cdot \text { Datos demográficos } \\
\text { Personalidad. Entre- } \\
\text { namiento musical }\end{array}$ & $\begin{array}{l}\text { Los rasgos de la personalidad de los } \\
\text { niños predijeron la duración del entre- } \\
\text { namiento musical } \\
\text { La apertura a la experiencia de los pa- } \\
\text { dres predijo la duración de la capacita- } \\
\text { ción de los niños } \\
\text { Las predisposiciones genéticas influyen } \\
\text { en la probabilidad de que un niño } \\
\text { tenga ciertas experiencias, como el } \\
\text { entrenamiento musical }\end{array}$ \\
\hline $\begin{array}{l}\text { Jennifer Zuk, Chris- } \\
\text { topher Benjamin } \\
\text { Arnold Kenyon } \\
\text { Nadine Gaab }\end{array}$ & 2014 & $\begin{array}{l}\text { Grupo } 1.30 \text { adultos } \\
(\mathrm{M}=24,8 . \mathrm{R}=18-35) \\
\cdot 15 \text { músicos (6 mujeres, } \\
9 \text { varones) } \\
\cdot 15 \text { no músicos (6 muje- } \\
\text { res, } 9 \text { varones) } \\
\cdot \text { Grupo } 2.27 \text { niños } \\
(\mathrm{M}=10.9 . \mathrm{R}=9-12) \\
\cdot 15 \text { músicos }(7 \text { mujeres, } \\
8 \text { varones }) \\
\cdot 15 \text { no músicos ( } 7 \text { muje- } \\
\text { res, } 8 \text { varones). }\end{array}$ & $\begin{array}{l}\cdot \text { Habilidades cogniti- } \\
\text { vas generales } \\
\cdot \text { Variables socioeconó- } \\
\text { micas } \\
\text {. Correlatos neuronales } \\
\text { (fMIR) }\end{array}$ & $\begin{array}{l}\text { Adultos: mejores resultados medidas } \\
\text { de flexibilidad cognitiva, memoria } \\
\text { de trabajo y fluidez verbal. Mejor } \\
\text { rendimiento en varios componentes de } \\
\text { funciones ejecutivas } \\
\text { Nińos: mejor rendimiento en mú- } \\
\text { sicos en medidas de fluidez verbal y } \\
\text { velocidad de procesamiento. Activa- } \\
\text { ción significativamente mayor en área } \\
\text { motora suplementaria, área precom- } \\
\text { plementaria y en el córtex prefrontal } \\
\text { ventrolateral derecho } \\
\text { Mayor activación cerebral en cambio } \\
\text { de tareas }\end{array}$ \\
\hline $\begin{array}{l}\text { Hua Yang; Weiyi Ma } \\
\text { Diankun Gong } \\
\text { Jiehui Hu; Dezhong } \\
\text { Yao }\end{array}$ & 2014 & $\begin{array}{l}250 \text { alumnos y alumnas } \\
\text { de primaria ( } 122 \text { mujeres } \\
\text { y } 128 \text { varones) } \\
\cdot 173 \text { no músicos } \\
\cdot 77 \text { músicos }\end{array}$ & $\begin{array}{l}\text { - Rendimiento } \\
\text { - Pintura } \\
\text { - Logro musical } \\
\text { - Educación materna } \\
\text { - Raven IQ test } \\
\text { - Compromiso aca- } \\
\text { démico fuera de la } \\
\text { escuela }\end{array}$ & $\begin{array}{l}\text { Los niños músicos superan a los no } \\
\text { músicos en logro musical y segundo } \\
\text { idioma }\end{array}$ \\
\hline
\end{tabular}




\begin{tabular}{|c|c|c|c|c|}
\hline Autores & Año & Participantes & Variables & Resultados \\
\hline $\begin{array}{l}\text { Cogo-Moreira, Hugo } \\
\text { Clara Regina Bran- } \\
\text { dão de Ávila } \\
\text { Ploubidis, George B. } \\
\text { Jair de Jesus Mari. }\end{array}$ & 2013 & $\begin{array}{l}235 \text { nińos con dificultades } \\
\text { de lectura. }(\mathrm{R}=8-10)\end{array}$ & $\begin{array}{l}\text { Dominios específicos } \\
\text { de percepción musical } \\
\text { (dominios temporales } \\
\text { y melódicos) } \\
\text {. Entrenamiento } \\
\text { musical }\end{array}$ & $\begin{array}{l}\text { Los dominios latentes generales } \\
\text { y melódicos predicen las habilidades } \\
\text { de lectura a nivel de palabra }\end{array}$ \\
\hline $\begin{array}{l}\text { Kathleen A. Corrigall } \\
\text { E. Glenn Schellen- } \\
\text { berg } \\
\text { Nicole M. Misura }\end{array}$ & 2013 & $\begin{array}{l}\text { Estudio } 1(78 \text { mujeres } \\
\text { y } 40 \text { varones })(\mathrm{M}=20) \\
\cdot 118 \text { adultos } \\
\text { Estudio } 2(82 \text { niñas } \\
\text { y } 85 \text { niños })(\mathrm{M}=11,5 . \\
\mathrm{R}=10-12) \\
\cdot 167 \text { nińos }\end{array}$ & $\begin{array}{l}\text { Información demo- } \\
\text { gráfica } \\
\cdot \text { Medidas cognitivas } \\
\cdot \text { Personalidad } \\
\cdot \text { Entrenamiento } \\
\text { musical }\end{array}$ & $\begin{array}{l}\text { Las diferencias individuales influyen } \\
\text { en quién toma lecciones de música } \\
\text { y por cuánto tiempo. } \\
\text { Las variables de personalidad son al } \\
\text { menos tan buenas como las variables } \\
\text { cognitivas en la predicción del entrena- } \\
\text { miento musical }\end{array}$ \\
\hline $\begin{array}{l}\text { Ingo Roden, Gunter } \\
\text { Kreutz } \\
\text { Stephan Bongard }\end{array}$ & 2012 & $\begin{array}{l}73 \text { niños }(\mathrm{M}=7,73) \\
\cdot 25 \text { grupo instrumental } \\
(11 \text { varones y } 14 \text { mujeres }) \\
\cdot 25 \text { grupo de ciencias } \\
\text { naturales ( } 14 \text { varones } \\
\text { y } 11 \text { mujeres) } \\
\cdot 23 \text { grupo control }\end{array}$ & $\begin{array}{l}\text { - Memoria visual/verbal } \\
\text { - Antecedentes socioe- } \\
\text { conómicos } \\
\text {. Coeficiente de inteli- } \\
\text { gencia }\end{array}$ & $\begin{array}{l}\text { Músicos: diferencias significativas en la } \\
\text { memoria verbal } \\
\text { Se encontraron diferencias entre los } \\
\text { grupos en las pruebas de memoria } \\
\text { visual } \\
\text { Músicos: se benefician de las mejoras } \\
\text { en habilidades de memoria verbal }\end{array}$ \\
\hline $\begin{array}{l}\text { Degé, Franziska } \\
\text { Kubicek, Claudia } \\
\text { Schwarzer, Gudrun. }\end{array}$ & 2011 & $\begin{array}{l}90 \text { nińos ( } 41 \text { varones } \\
\text { y } 49 \text { mujeres })(\mathrm{M}=11,40 \\
\text { y } \mathrm{R}=9-12)\end{array}$ & $\begin{array}{l}\text { - Inteligencia } \\
\text { Funciones ejecutivas } \\
\text { diferentes (cambio de } \\
\text { grupo, atención se- } \\
\text { lectiva, planificación, } \\
\text { inhibición y fluidez) }\end{array}$ & $\begin{array}{l}\text { Músicos: aumento significativo en las } \\
\text { medidas de función ejecutiva, atención } \\
\text { selectiva e inhibición } \\
\text { Las lecciones de música poseen } \\
\text { influencia positiva sobre las funciones } \\
\text { ejecutivas y, a su vez, mejoran el rendi- } \\
\text { miento en las pruebas de inteligencia }\end{array}$ \\
\hline $\begin{array}{l}\text { E. Glenn } \\
\text { Schellenberg }\end{array}$ & 2011 & $\begin{array}{l}106 \text { niños ( } 54 \text { varones; } 52 \\
\text { mujeres) }(\mathrm{R}=9-12) \\
\cdot 50 \text { clases de música ( } 26 \\
\text { varones, } 24 \text { mujeres) } \\
\cdot 56 \text { sin clases de música } \\
\text { (28 niños, } 28 \text { niñas) }\end{array}$ & $\begin{array}{l}\cdot \text { Funciones ejecutivas } \\
\cdot \text { Inteligencia } \\
\cdot \text { Entrenamiento } \\
\text { musical }\end{array}$ & $\begin{array}{l}\text { Músicos: coeficientes intelectuales } \\
\text { más altos que sus congéneros sin } \\
\text { entrenamiento musical y la ventaja se } \\
\text { incrementaba con la realización de las } \\
\text { subpruebas de CI } \\
\text { La asociación entre el entrenamiento } \\
\text { musical y la función ejecutiva fue } \\
\text { insignificante } \\
\text { Estos resultados no respaldan la } \\
\text { hipótesis de que la asociación entre el } \\
\text { entrenamiento musical y el coeficiente } \\
\text { de inteligencia está mediada por la } \\
\text { función ejecutiva }\end{array}$ \\
\hline Helmrich, Barbara H. & 2010 & $\begin{array}{l}6.026 \text { estudiantes de } \\
\text { noveno grado (Sistema } \\
\text { Americano, } \mathrm{R}=14-15) \\
3 \text { grupos por tipo de } \\
\text { formación: } \\
\cdot 1.952 \text { músicos } \\
\cdot 1.287 \text { con instrucción } \\
\text { coral } \\
\cdot 2.787 \text { sin formación } \\
\text { musical }\end{array}$ & $\begin{array}{l}\text { - Rendimiento acadé- } \\
\text { mico de algebra } \\
\text { - Instrucción musical } \\
\text { - Etnia }\end{array}$ & $\begin{array}{l}\text { Los estudiantes con formación musi- } \\
\text { cal: superaron a los que no experimen- } \\
\text { taron ninguna formación musical } \\
\text { Diferencias significativas en el logro de } \\
\text { álgebra entre los grupos instrumentales } \\
\text { y no instruccionales y entre los grupos } \\
\text { coral y ninguno de instrucción } \\
\text { La mayor diferencia de medias entre } \\
\text { dos grupos de comparación se produjo } \\
\text { entre los grupos instrumentales y sin } \\
\text { instrucción de afroamericanos }\end{array}$ \\
\hline
\end{tabular}




\begin{tabular}{|c|c|c|c|c|}
\hline Autores & Año & Participantes & Variables & Resultados \\
\hline $\begin{array}{l}\text { Selfhout, Maarten } \\
\text { H.W. } \\
\text { Branje, Susan J.T. } \\
\text { ter Bogt, Tom F.M. } \\
\text { Meeus, Wim H.J. }\end{array}$ & 2009 & $\begin{array}{l}283 \text { parejas de amigos } \\
\text { adolescentes (varones el } \\
49,5 \% \text { y } 50,8 \% \text { mujeres) } \\
(\mathrm{M}=12.97)\end{array}$ & $\begin{array}{l}\text { - Entrenamiento } \\
\text { musical } \\
\text { Preferencias de di- } \\
\text { mensiones musicales } \\
\text { específicas } \\
\text { - Patrón de la forma- } \\
\text { ción y estabilidad de } \\
\text { la amistad }\end{array}$ & $\begin{array}{l}\text { La similitud en las preferencias musi- } \\
\text { cales está relacionada con la formación } \\
\text { de la amistad y no con la interrupción } \\
\text { de la amistad }\end{array}$ \\
\hline $\begin{array}{l}\text { Darby E. Southgate } \\
\text { Vincent J. Roscigno }\end{array}$ & 2009 & $\begin{array}{l}\text { Estudio longitudinal de } \\
20.000 \text { estudiantes de } \\
\text { primaria durante primero, } \\
\text { tercero y quinto grado. } \\
25.000 \text { adolescentes (sis- } \\
\text { tema norteamericano) }\end{array}$ & $\begin{array}{l}\cdot \text { Logros } \\
\cdot \text { Formación musical } \\
\cdot \text { Rendimiento acadé- } \\
\text { mico }\end{array}$ & $\begin{array}{l}\text { La participación de la música, tanto } \\
\text { dentro como fuera de la escuela, se } \\
\text { asocia con medidas de logros académi- } \\
\text { cos entre niños y adolescentes }\end{array}$ \\
\hline $\begin{array}{l}\text { Marie Forgeard, Ellen } \\
\text { Winner, Andrea } \\
\text { Norton, Gottfried } \\
\text { Schlaug }\end{array}$ & 2008 & $\begin{array}{l}59 \text { niños }(\mathrm{M}=9,96 . \\
\mathrm{R}=8,73-11,31) \\
\cdot 41 \text { músicos ( } 19 \text { varones } \\
\text { y } 22 \text { nińas) } \\
\cdot 18 \text { no músicos ( } 7 \text { niñas } \\
\text { y } 11 \text { niños) }\end{array}$ & $\begin{array}{l}\text { Características socioe- } \\
\text { conómicas } \\
\text { - Tiempo de entrena- } \\
\text { miento musical } \\
\text {. Funciones ejecutivas }\end{array}$ & $\begin{array}{l}\text { Músicos puntuaciones altas en las } \\
\text { tareas de función ejecutiva } \\
\text { Músicos con } 3 \text { años de formación: } \\
\text { puntuaciones altas y significativas en } \\
\text { habilidades de discriminación auditiva, } \\
\text { motricidad fina, vocabulario y razona- } \\
\text { miento no verbal }\end{array}$ \\
\hline $\begin{array}{l}\text { Sylvain Moreno, } \\
\text { Carlos Marques, } \\
\text { Andreia Santos, } \\
\text { Manuela Santos, Sao } \\
\text { Luís Castro y Mirei- } \\
\text { lle Besson }\end{array}$ & 2008 & $\begin{array}{l}32 \text { niños }(M=8,42) \\
\text { Grupo } 1 . \text { Músicos } \\
\cdot 16 \text { ( } 9 \text { varones y } 7 \mathrm{mu}- \\
\text { jeres) } \\
\text { Grupo } 2 \text {. Pintura } \\
\cdot 16 \text { (10 varones y } 6 \text { muje- } \\
\text { res) }\end{array}$ & $\begin{array}{l}\cdot \text { Diferencias funcio- } \\
\text { nales } \\
\cdot \text { Lectura } \\
\cdot \text { Discriminación tonal } \\
\cdot \text { Entrenamiento } \\
\text { musical }\end{array}$ & $\begin{array}{l}\text { Música: mejora significativa del } \\
\text { comportamiento y en el desarrollo } \\
\text { de procesos neuronales en un patrón } \\
\text { específico de ondas cerebrales. } \\
\text { Transferencia positiva de la música al } \\
\text { habla y resalta la influencia del entre- } \\
\text { namiento musical } \\
\text { Aumento de plasticidad en el grupo de } \\
\text { música }\end{array}$ \\
\hline $\begin{array}{l}\text { Peter Gouzouasis, } \\
\text { Martin Guhn } \\
\text { Nand Kishor }\end{array}$ & 2007 & $\begin{array}{l}\text { Estudio de cohortes }(\mathrm{R}= \\
17-18) \\
\text { Último curso de estudios } \\
\text { preuniversitarios }\end{array}$ & $\begin{array}{l}\text { Participación musical } \\
\text {. Logro musical } \\
\text { - Rendimiento acadé- } \\
\text { mico }\end{array}$ & $\begin{array}{l}\text { La formación musical se asoció con } \\
\text { un mejor rendimiento académico y } \\
\text { una predicción de las puntuaciones en } \\
\text { logro académico } \\
\text { El tiempo dedicado a la formación } \\
\text { musical no impide el logro académi- } \\
\text { co, sino que fomenta la excelencia } \\
\text { académica }\end{array}$ \\
\hline $\begin{array}{l}\text { Stoeber, J. } \\
\text { Eismann, U. }\end{array}$ & 2007 & $\begin{array}{l}146 \text { participantes }(59 \\
\text { varones y } 87 \text { mujeres }) \\
(\mathrm{M}=16,2 ; \mathrm{R}=13-20)\end{array}$ & $\begin{array}{l}\cdot \text { Perfeccionismo } \\
\cdot \text { Motivación } \\
\cdot \text { Esfuerzo y logro } \\
\text { - Angustia }\end{array}$ & $\begin{array}{l}\text { Reacciones negativas a la imperfección } \\
\text { asociadas con: motivación externa, an- } \\
\text { siedad de rendimiento y otras formas } \\
\text { de angustia } \\
\text { La búsqueda de la perfección asociada } \\
\text { con la motivación intrínseca, el esfuer- } \\
\text { zo invertido y el logro musical }\end{array}$ \\
\hline $\begin{array}{l}\text { E. Glenn Schellen- } \\
\text { berg }\end{array}$ & 2004 & $\begin{array}{l}144 \text { niños }(M=6) \\
\text { Grupos de entrenamiento: } \\
\cdot 1 \text { y } 2 \text { Música } \\
\cdot 3 \text { Teatro } \\
\cdot 4 \text { Grupo control }\end{array}$ & $\begin{array}{l}\text { - Inteligencia } \\
\text { - Entrenamiento } \\
\text { musical } \\
\cdot \text { Lecciones de teatro } \\
\text { - Rendimiento acadé- } \\
\text { mico }\end{array}$ & $\begin{array}{l}\text { Grupo de música: exhibieron mayores } \\
\text { aumentos en el CI a gran escala desde } \\
\text { las lecciones previas a las posteriores } \\
\text { Estos resultados obtenidos por medio } \\
\text { de subpruebas de CI, puntajes de } \\
\text { índice y una medida estandarizada de } \\
\text { rendimiento académico }\end{array}$ \\
\hline
\end{tabular}




\begin{tabular}{|c|c|c|c|c|}
\hline Autores & Año & Participantes & Variables & Resultados \\
\hline $\begin{array}{l}\text { Yim-Chi Ho, Mei- } \\
\text { Chun Cheung } \\
\text { Agnes S. Chan }\end{array}$ & 2003 & $\begin{array}{l}90 \text { varones hombres dies- } \\
\text { tros }(\mathrm{M}=10,66 . \\
\mathrm{R}=6-15) \\
.45 \text { músicos } \\
.45 \text { no músicos }\end{array}$ & $\begin{array}{l}\text { - Inteligencia } \\
\text { - Demografía } \\
\text { - Memoria verbal } \\
\text { - Duración del entrena- } \\
\text { miento } \\
\text { - Memoria visual }\end{array}$ & $\begin{array}{l}\text { Músicos: mejor memoria verbal pero } \\
\text { no visual que los no músicos. Tam- } \\
\text { bién después de un año esta diferencia } \\
\text { aumentó. En los que dejaron el estudio } \\
\text { musical se estancó }\end{array}$ \\
\hline $\begin{array}{l}\text { Adrian C. North } \\
\text { David J. Hargreaves } \\
\text { Susan A. O’Neill }\end{array}$ & 2000 & $\begin{array}{l}2.465 \text { adolescentes } \\
(1.149 \text { hombres, } 1.266 \\
\text { mujeres, } 50 \text { participantes } \\
\text { no declararon su sexo }) \\
(\mathrm{R}=13-14) \\
\text { Más del } 50 \% \text { tocaban un } \\
\text { instrumento actualmente } \\
\text { o lo habían hecho con } \\
\text { anterioridad }\end{array}$ & $\begin{array}{l}\text { - Grado de participa- } \\
\text { ción en actividades } \\
\text { musicales } \\
\text { - Importancia de la } \\
\text { música en relación } \\
\text { con otras actividades } \\
\text {. Importancia de facto- } \\
\text { res de imagen social }\end{array}$ & $\begin{array}{l}\text { La música es importante para los } \\
\text { adolescentes, y esto se debe a que les } \\
\text { permite retratar una «imagen» para el } \\
\text { mundo exterior y satisfacer sus necesi- } \\
\text { dades emocionales }\end{array}$ \\
\hline
\end{tabular}

y cols., 2014; Cogo-Moreira y cols., 2013; Helmrich y cols., 2010; Southgate y Roscigno, 2009).

Se observan un buen número de aportaciones positivas ante la influencia del estudio musical en el rendimiento académico, pero debemos ser cautos ante la interpretación de estos datos, dado que algún estudio contradice estas afirmaciones tan positivas, y pese a destacar la relación positiva de esta formación mediante su asociación con el concepto de autoestima, presentan datos contradictorios en el rendimiento académico (Costa-Giomi, 2016).

\section{Música y cognición}

A nivel cognitivo los estudios muestran cómo los niños con formación musical presentan altas habilidades cognitivas, mayor motivación y capacidad de concentración, así como un aumento del coeficiente intelectual (Jaschke y cols., 2018; Degé y cols., 2011; Schellenberg, 2011; Schellenberg, 2004). Respecto a las funciones ejecutivas, los datos mostraron mejores puntuaciones de los músicos en pruebas de función ejecutiva, atención selectiva e inhibición y mantenimiento (Herrero y Carriedo, 2018; Jaschke y cols., 2018; Dawn y cols., 2017; Zuk y cols., 2014; Degé y cols., 2011).

También referenciaron una disminución del efecto de la congruencia, lo que sugiere que el entrenamiento musical está relacionado con el control inhibitorio cognitivo (Joret y cols., 2017). Se encontraron diferencias significativas en memoria verbal, y también a nivel de memoria visual, pero estas últimas no de forma significativa, aunque sí de manera notable (Roden y cols., 2012; Ho y cols., 2003).

Los estudios también correlacionan el tiempo de formación musical con su influencia a nivel cognitivo, viéndose que aquellos niños que tenían una formación de más de tres años reflejaban mayores puntuaciones a nivel de funciones ejecutivas, específicamente en tareas de habilidad de discriminación auditiva, motricidad fina, vocabulario y razonamiento no verbal y a una mejor codificación de los estímulos visuales y auditivos (Mandikal Vasuki y cols., 2017; Corrigal y Schellenberg, 2015; Corrigall y cols., 2013; Forgeard y cols., 2008).

En términos del concepto de perfeccionamiento, los niños con formación musical se asociaron con la búsqueda de la perfección, que se relacionó con la motivación intrínseca, el esfuerzo invertido y el logro musical (Degé y Schwarzer, 2017; Stoeber y Eismann, 2007).

También se ha observado que los niños expuestos a un programa de formación musical presentan mejor autocontrol y reducción de conductas conflictivas, así como una mayor plasticidad cerebral (Alemán y cols., 2017; Roden y cols., 2016; Moreno, 2008). En los adolescentes, se relaciona la música como una expresión de su imagen y una manera de satisfacer sus necesidades emocionales. Además, se asoció que la similitud de preferencias musicales tenía una relación directa con la formación de la amistad, pero, por el contrario, no presentaba relación alguna con la interrupción de esta (Selfhout y cols., 2009; North y cols., 2000).

Como se puede ver a partir de lo expuesto hasta ahora, todo parece indicar que el entrenamiento musical promueve cambios a nivel cognitivo en los niños que realizan esta formación, en comparación con los niños que no toman lecciones de música. Este hecho repercutiría, a su vez, en las diferencias que hemos descrito a nivel de rendimiento académico, sugiriendo la posibilidad de que también se produzcan cambios estructurales en el cerebro.

\section{Música y neuroanatomía}

Por último, los estudios de neuroanatomía muestran evidencias claras de los cambios estructurales producidos en el cerebro por la formación musical. Mediante técnicas de neuroimagen (fMRI) se han explorado los componentes específicos de las funciones cognitivas y las habilidades musicales, como la atención sostenida y la flexibilidad 
cognitiva, y se han encontrado cambios macro- y microestructurales en el cerebro, cambios en la red de control cognitivo a nivel cerebral, así como una activación neuronal más fuerte en tareas de inhibición cognitiva. Estos estudios también revelaron que estos cambios no son atribuibles a rasgos biológicos ya preexistentes (Habibi y cols., 2018; Habibi y cols., 2017; Sachs et al., 2017; Zuk y cols., 2014).

\section{Discusión}

Los resultados extraídos de esta investigación resaltan la importancia del estudio musical en la etapa de formación académica. Estos datos reflejan los cambios que produce la formación musical en este período, siguiendo lo que parece simular un efecto cascada, es decir, los estudios en neuroanatomía muestran cómo se produce un aumento de la plasticidad cerebral entre otros cambios a nivel microscópico y macroscópico. Estos cambios a nivel cerebral serían concomitantes a un cambio en las habilidades cognitivas, como son la atención sostenida, los procesos de inhibición, motivación intrínseca y memoria verbal, en general, una mejora en las puntuaciones y habilidades en funciones ejecutivas, las cuales son necesarias para el aprendizaje. Estas mejoras se observan en el rendimiento académico, ya que, como hemos podido comprobar, los estudiantes de música presentan mayores puntuaciones y destacan, sobre todo, en asignaturas como matemáticas, segundo idioma, arte o ciencias de la naturaleza.

Por ello, estos datos sugieren que la formación musical no solo aporta resultados positivos dentro del ámbito académico, sino también en habilidades cognitivas y plasticidad neuronal que pueden extrapolarse a otras actividades de la vida diaria, $y$ en un futuro en el rendimiento y competencias a nivel laboral. Las investigaciones futuras deberían considerar el efecto del aprendizaje de la música en el rendimiento académico, teniendo en cuenta las diferencias (cognitivas, de personalidad, académicas y sociodemográficas) entre los estudiantes que aprenden música y los que no. De hecho, cuando se tiene en cuenta esta diferencia, algunos autores han mencionado que quienes estudian música ya están diferenciados en términos de rendimiento académico previo (Fitzpatrick, 2006; Helmrich, 2010), inteligencia (Corrigall y cols., 2013; Schellenberg y Weiss, 2013) y personalidad (Corrigal y Schellenberg, 2015; Corrigall y cols., 2013). La importancia de esta consideración reside, en general, en la discrepancia entre los estudios encontrados que sugieren que son muchas las variables que modulan estos efectos producidos por el entrenamiento musical, como sería el tiempo de formación y de práctica, el tipo de formación, ya sea instrumental o grupal, y, en el caso de ser instrumental, la diferenciación del tipo de instrumento seleccionado por el alumno. Además, los estudios de neuroanatomía confirman cambios a nivel cerebral debidos a la formación musical (Habibi et al., 2018; Habibi et al.,
2017; Sachs et al., 2017; Zuk et al., 2014), lo que nos lleva a considerar la posibilidad de que estos cambios de plasticidad y espesor cortical en los niños y niñas pueda ser en un futuro un factor de protección para enfermedades neurodegenerativas o el envejecimiento normativo. Sin embargo, no debemos olvidar las diferencias individuales de los alumnos/as al tener en cuenta la producción de estos cambios y que el entrenamiento musical no es el único factor promotor de estos.

Por todo ello, concluimos que, tras el análisis de la literatura, la formación musical parece ser una gran herramienta en la formación de los estudiantes en edad escolar, que no solo les beneficia a nivel académico, sino también a nivel de desarrollo cognitivo y de desarrollo cerebral.

\section{Referencias}

Alemán, X., Duryea, S., Guerra, N. G., McEwan, P. J., Muñoz, R., Stampini, M. y Williamson, A. A. (2017). The Effects of Musical Training on Child Development: a Randomized Trial of El Sistema in Venezuela. Prevention Science, 18(7), 865-878. https://doi.org/10.1007/s11121-016-0727-3

Cogo-Moreira, H., Clara, R. B., Ploubidis, G. B. y Jair de, J. M. (2013). Pathway evidence of how musical perception predicts word-level reading ability in children with reading difficulties. PLoS ONE, 8(12).

http://dx.doi.org/10.1371/journal.pone.0084375

Corrigall, K. A., Schellenberg, E. G. y Misura, N. M. (2013). Music Training, Cognition, and Personality. Frontiers in Psychology, 4 (abril).

https://doi.org/10.3389/fpsyg.2013.00222

Corrigall, K. A. y Schellenberg, E. G. (2015). Predicting who takes music lessons: Parent and child characteristics. Frontiers in Psychology, 6 (marzo), 1-8. https://doi.org/10.3389/fpsyg.2015.00282

Costa-Giomi, E. (2016). Effects of three years of piano instructiy on on children's academic achievement, school performance and self-esteem. Psychology of music, 32(2), 139-152. https:// doi.org/http://dx.doi.org/10.1108/17506200710779521

Degé, F. y Schwarzer, G. (2017). The influence of an extended music curriculum at school on academic self-concept in 9to 11-year-old children. Musicae Scientiae, 22(3), 305-321. https://doi.org/10.1177/1029864916688508

Degé, F., Kubicek, C. y Schwarzer, G. (2011). Music lessons and intelligence: a relation mediated by executive functions. Music Perception, 29(2), 195-201.

https://search.proquest.com/docview/911784586?accountid $=14777$

Dos Santos-Luiz, C., Mónico, L. S. M., Almeida, L. S. y Coimbra, D. (2016). Exploring the long-term associations between adolescents' music training and academic achievement. Musicae Scientiae, 20(4), 512-527. https://doi.org/10.1177/1029864915623613

Figueroba, A. (2018). Cognición: definición, procesos principales y funcionamiento. 13/05/2018, de Psicología y Mente. Sitio web: https://psicologiaymente.net/inteligencia/cognicion-definicion-procesos

Fitzpatrick, K. R. (2006). The effect of instrumental music participation and socio-economic status on Ohio fourth-, 
sixth-, and ninth-grade proficiency test performance. Journal of Research in Music Education, 54, 73-84. https://doi. org/10.1177/002242940605400106

Forgeard, M., Winner, E., Norton, A. y Schlaug, G. (2008). Practicing a musical instrument in childhood is associated with enhanced verbal ability and nonverbal reasoning. PLoS ONE, 3(10), 1-8. https://doi.org/10.1371/journal. pone.0003566

Gouzouasis, P., Guhn, M. y Kishor, N. (2007). The predictive relationship between achievement and participation in $\mathrm{mu}$ sic and achievement in core Grade 12 academic subjects. Music Education Research, 9(1), 81-92.

https://doi.org/10.1080/14613800601127569

Habibi, A., Damasio, A., Ilari, B., Elliott Sachs, M. y Damasio, H. (2018). Music training and child development: a review of recent findings from a longitudinal study. Annals of the New York Academy of Sciences, 1-9.

https://doi.org/10.1111/nyas.13606

Habibi, A., Damasio, A., Ilari, B., Veiga, R., Joshi, A. A., Leahy, R. M. y Damasio, H. (2017). Childhood Music Training Induces Change in Micro and Macroscopic Brain Structure: Results from a Longitudinal Study. Cerebral Cortex, (November), 1-12. https://doi.org/10.1093/cercor/bhx286

Hallam, S. (2010). The power of music: Its impact on the intellectual, social and personal development of children and young people. International JournalofMusic Education, 28(3), 269-289. https://doi.org/10.1177/0255761410370658

Hallam, S. y Rogers, K. (2016). The impact of instrumental music learning on attainment at age 16: A pilot study. British Journal of Music Education, 33(3), 247-261. http://dx. doi.org/10.1017/S0265051716000371

He, S.Q., Dum, R.P. y Strick, P.L (1995). Topographic organization of corticospinal projections from the frontal lobe: motor areas on the medial surface of the hemisphere. J. Neurosci., 15, 3284-3306.

Helmrich, B. H. (2010). Window of opportunity? Adolescence, music, and Algebra. Journal of Adolescent Research, 25(4), 557-577.

https://doi.org/10.1177/0743558410366594

Herrero, L. y Carriedo, N. (2018). Learning and Individual differences in updating processes between musicians and non-musicians from late childhood to adolescence. Learning and Individual Differences, 61(10), 188-195. https://doi.org/10.1016/j.lindif.2017.12.006

Ho, Y. C., Cheung, M.C. y Chan, A. S. (2003). Music training improves verbal but not visual memory: Cross-sectional and longitudinal explorations in children. Neuropsychology, 17(3), 439-450. https://doi.org/10.1037/0894-4105.17.3.439

Holochwost, S. J., Wolf, D., Volpe, V. V, Holochwost, S. J., Propper, C. B. y Fisher, K. R. (2017). Music education, acah demic achievement, and executive functions. Psychology of Aesthetics, Creativity, and the Arts, 11(2), 147-166. https:// doi.org/10.1037/aca0000112

Jaschke, A. C., Honing, H. y Scherder, E. J. A. (2018). Longitudinal Analysis of Music Education on Executive Functions in Primary School Children. Frontiers in Neuroscience, 12 (febrero). https://doi.org/10.3389/fnins.2018.00103

Joret, M.-E., Germeys, F. y Gidron, Y. (2017). Cognitive inhibitory control in children following early childhood music education. Musicae Scientiae, 21(3), 303-315. https:// doi.org/10.1177/1029864916655477
Luppino, G., Matelli, M., Camarda, R. M., Gallese, V. y Rizzolatti, G (1991). «Multiple representations of body movements in mesial area 6 and the adjacent cingulate cortex: an intracortical microstimulation study in the macaque monkey». J. Comp. Neurol. 311(4), 463-482. doi:10.1002/cne.903110403.

Mandikal Vasuki, P. R., Sharma, M., Ibrahim, R. y Arciuli, J. (2017). Statistical learning and auditory processing in children with music training: An ERP study. Clinical Neurophysiology, 128(7), 1270-1281.

https://doi.org/10.1016/j.clinph.2017.04.010

Miendlarzewska, E. A. y Trost, W. J. (2014). How musical training affects cognitive development: Rhythm, reward and other modulating variables. Frontiers in Neuroscience, 7(8 JAN), 1-18. https://doi.org/10.3389/fnins.2013.00279

Moher, D., Liberati, A., Tetzlaff, J., Altman, D. G., Altman, D., Antes, G. et al. (2009). Preferred reporting items for systematic reviews and meta-analyses: The PRISMA statement. PLoS Medicine, 6(7).

Moreno, S., Marques, C., Santos, A., Santos, M., Castro, S. L. y Besson, M. (2009). Musical training influences linguistic abilities in 8-year-old children: More evidence for brain plasticity. Cerebral Cortex, 19(3), 712-723.

https://doi.org/10.1093/cercor/bhn120

North, A. C., Hargreaves, D. J. y O'Neill, S. A. (2000). The importance of music to adolescents. British Journal of Educational Psychology, 70, 255. https://search.proquest.com/ docview/216967057? accountid $=14777$

Okada, B. M. y Slevc, L. R. (2017). Musical training: Contributions to executive function. En M. Bunting, J. Novick, M. Dougherty, \& R. W. Engle (eds.), An Integrative Approach to Cognitive and Working Memory Training: Perspectives from Psychology, Neuroscience, and Human Development. Nueva York, NY: Oxford University Press.

Ribeiro, F. S. y Santos, F. H. (2017). Enhancement of numeric cognition in children with low achievement in mathematic after a non-instrumental musical training. Research in Developmental Disabilities, 62, 26-39.

https://doi.org/10.1016/j.ridd.2016.11.008

Roden, I., Zepf, F. D., Kreutz, G., Grube, D. y Bongard, S. (2016). Effects of music and natural science training on aggressive behavior. Learning and Instruction, 45, 85-92. https://doi.org/10.1016/j.learninstruc.2016.07.002

Roden, I., Kreutz, G. y Bongard, S. (2012). Effects of a schoolbased instrumental music program on verbal and visual memory in primary school children: A longitudinal study. Frontiers in Psychology, 3(DEC), 1-9.

https://doi.org/10.3389/fpsyg.2012.00572

Rose, D., Jones Bartoli, A. y Heaton, P. (2017). Measuring the impact of musical learning on cognitive, behavioural and socio-emotional wellbeing development in children. Psychology of Music. https://doi.org/10.1177/0305735617744887

Sachs, M., Kaplan, J., Der Sarkissian, A. y Habibi, A. (2017). Increased engagement of the cognitive control network associated with music training in children during an fMRI Stroop task. PLoS ONE.

https://doi.org/10.1371/journal.pone.0187254

Shellenberg, E. G. (2011). Examining the association between music lessons and intelligence. British Journal of Psychology, 102(3), 283-302.

https://doi.org/10.1111/j.2044-8295.2010.02000.x 
Schellenberg, E. G. (2004). Music lessons enhance IQ. Psychological Science, 8(15), 511-514. https://doi.org/10.1111/ j.0956-7976.2004.00711.x

Schellenberg E. G. y Weiss M. W. (2013). Music and Cognitive Abilities. Psychology of Music, 3, 499-550. http://dx.doi. org/10.1016/B978-0-12-381460-9.00012-2

Selfhout, M. H. W., Branje, S. J. T., Ter Bogt, T. F. M y Meeus, W. H. J. (2009). The role of music preferences in early adolescents' friendship formation and stability. Journal of Adolescence, 32(1), 95-107.

https://doi.org/10.1016/j.adolescence.2007.11.004

Southgate, D. E. y Roscigno, V. J. (2009). The impact of music on childhood and adolescent achievement. Social Science Quarterly, 90(1), 4-21.

https://doi.org/10.1111/j.1540-6237.2009.00598.x

Stoeber, J. y Eismann, U. (2007). Perfectionism in young musicians: Relations with motivation, effort, achievement, and distress. Personality and Individual Differences, 43(8), 21822192. https://doi.org/10.1016/j.paid.2007.06.036

Urrútia G. y Bonfill X. (2013). La declaración prisma: Un paso adelante en la mejora de las publicaciones de la Revista Española de Salud Pública. Revista Española de Salud Pública, 87(2), 99-102.

Zuk, J., Benjamin, C., Kenyon, A. y Gaab, N. (2014). Behavioral and neural correlates of executive functioning in musicians and non-musicians. PLoS ONE, 9(6). http://dx. doi. org/10.1371/journal.pone.0099868

Yang, H., Zuk, J., Benjamin, C., Kenyon, A., Gaab, N. W. y Wong, Y. (2014). A longitudinal study on children's music training experience and academic development. PLoS ONE, $4(8), 4-10$

https://doi.org/10.1371/journal.pone.0099868 